\title{
Gestão por Competências na Administração Pública de Portugal: UMA ANÁlISE A PARTIR DO CICLO INTERLIGADO DE LEGITIMAÇÃO E DE VALIDAÇÃO
}

\section{Luciano Munck}

Estudante de Pós-Doutorado na University of Western. London, Canadá. Professor da Universidade Estadual de Londrina, PR. London, Canada.E-mail: lmunck@ivey.ca; munck@uel.br

\section{Bárbara Galleli}

Doutoranda em Administração do Programa de Pós-Graduação em Administração. Universidade de São Paulo FEA/USP. São Paulo, SP. Brasil.E-mail: b.gallelidias@gmail.com

\section{Rafael Borim-de-Souza}

Doutor em Administração pelo Programa de Pós-Graduação em Administração da Universidade Federal do Paraná. Universidade Federal do Paraná. Curitiba, PR. Brasil. E-mail: rafaborim@yahoo.com

\section{Resumo}

O objetivo deste artigo é analisar o modelo de gestão de pessoas por competências da Administração Pública de Portugal a partir do Ciclo Interligado de Legitimação e de Validação Qualitativa. As categorias consideradas foram: definição constitutiva, validade de construto, composta pela validade de conteúdo, validade de face e confiabilidade e validade preditiva. A análise do modelo de gestão por competências de Portugal permitiu a identificação de pontos críticos em suas premissas, propostas e objetivos. Em suma, constatou-se que o modelo utilizado pela Administração Pública de Portugal tem comprovada a validade das definições constitutiva e operacional e a validade de face. Contudo, foram identificadas fragilidades na validade de construto, especificamente na validade de conteúdo, na confiabilidade e na validade preditiva. Portanto, conclui-se que erros podem circundar o modelo por completo. Em seu âmbito, o presente artigo identificou e discutiu questões centrais no que se refere à implantação e à validação de modelos de competências, pertinentes tanto para organizações públicas quanto privadas.

Palavras-chave: Modelos de Gestão por Competências. Validação. Administração Pública de Portugal.

\section{Abstract}

The objective of this article is to analyze the model of people management by competences of Portugal Public Administration from the Interconnected Cycle of Legitimation and Qualitative Validation. The categories considered were: constitutive definition, construct validity, composed by face validity, content validity, face validity and reliability, and predictive validity. The analysis of Portugal competence management model has allowed critical points to be identified between premises, purposes and objectives of it. In sum, from this study it was concluded that errors can circle the model completely, since has been verified some weaknesses and limitations in construct validity, specifically in the content validity, and in predictive validity, on which the competence management model was developed. In its scope, this article has identified issues that need to be emphasized, as the process of competence defining, and discussed key issues regarding the implementation and validation of competence models, for example, in relation to contributions of the model for individual and organizational performances, relevant to both public and private organizations.

Keywords: Competence Management Model. Validation. Portugal Public Administration. 


\section{INTRODUÇÃo}

Autores como Kochanski (1997), Shippmann et al. (2000) e Markus, Cooper-Thomas e Allpress (2005) afirmam que ainda há poucas evidências para sugerir que modelos de gestão de ou por competências fornecem qualquer capacidade preditiva incremental sobre as medidas existentes para indicar melhorias no desempenho global empresarial. Acrescentam ainda que seu uso inadequado implica grande desordem sobre suas reais finalidades.

Uma varredura inicial na literatura pesquisada permitiu observar que a consolidação de modelos de gestão de, ou por competências, como referência principal para a gestão de pessoas experimenta diversos desafios que poderiam ou até deveriam se tornar grandes temas para uma extensa agenda de pesquisa. (DREJER, 2002; MILLS et al., 2002; DUTRA, 2004; FLEURY; FLEURY, 2008)

Munck e Munck (2008) afirmam que a exigência de novos padrões de competência que transpassam as esferas pública e privada contribui sensivelmente para o crescimento de estudos teóricos e empíricos que refletem sobre a articulação entre elas. No entanto, embora a maior parte da literatura posicione a lógica da competência e seus respectivos modelos como substitutos e superiores às abordagens clássicas de gestão, sua aplicação como instrumento fundamental para subsidiar decisões relacionadas à gestão de pessoas e à empresa como um todo tem confundido muitas organizações, sejam do setor privado ou do setor público. Esse ponto é principalmente ressaltado quando persiste o questionamento sobre a relação entre os objetivos propostos pelos modelos de gestão por competências e seus respectivos resultados.

Com o intuito de ampliar conhecimentos sobre a relação de modelos de competências com sua eficácia nas organizações, este artigo faz uso da estrutura chamada Ciclo Interligado de Legitimação e Validação Qualitativa de modelos de competências, oriunda no modelo de validação proposto por Markus, Cooper-Thomas e Allpress (2005) e aprimorada por Munck, Munck e Borim-de-Souza (2011) a fim de analisar o modelo de gestão de pessoas por competências da Administração Pública de Portugal. O referido ciclo possui a seguinte configuração: definição constitutiva e operacional; validade de construto, a qual envolve as validades de conteúdo e de face, e a de confiabilidade; $e$, por fim, a validade preditiva.

O modelo de gestão por competências, selecionado para estudo, devido aos detalhes de sua descrição, foi o desenvolvido pelo Departamento de Recrutamento e Seleção de Pessoal da Administração Pública de Portugal (DGAP). O DGAP, a partir da aplicação de estudos de follow-up (acompanhamento) em grupos profissionais mais frequentemente avaliados considerou oportuna a implantação de um modelo de gestão por competências com vistas a introduzir maior rigor no diagnóstico das necessidades e na avaliação dos resultados da formação profissional. (DGAP, 2006)

É importante ressaltar que o objetivo principal deste artigo limitou-se a verificar possíveis pontos críticos do modelo de gestão por competências estudado frente às exigências propostas pelo ciclo interligado de legitimação e validação qualitativa proposto por Munck, Munck e Borim-de-Souza (2011). Para um melhor aprofundamento do tema em análise, o texto disposto ao longo do artigo foi dividido em seis seções, sendo elas: introdução; procedimentos metodológicos; o ciclo interligado de legitimação e validação qualitativa de modelos de competências; o modelo de gestão competências da Administração Pública de Portugal; análise do modelo de gestão competências da Administração Pública de Portugal por meio do ciclo interligado de validação e legitimação; e considerações finais, sugestões de estudos futuros e implicações para a Administração.

\section{Procedimentos Metodológicos}

Apresenta-se uma síntese dos procedimentos metodológicos, realizados no período de setembro a novembro de 2011, pois ao longo do artigo serão apresentadas informações complementares pertinentes.

Mediante o objetivo de analisar o modelo de gestão de pessoas articulado por competências da Administração Pública de Portugal, por meio do ciclo interligado de legitimação $e$ validação qualitativa de modelos de competências, em termos metodológicos, realizou-se uma pesquisa de natureza descritiva por estar munida do interesse de verificar e descrever as características de um fenômeno em determinada realidade (RICHARDSON et al., 2008), no caso, pontos críticos do modelo de gestão por competências da Administração Pública de Portugal. 
Como fontes de dados utilizou-se a pesquisa teórica por meio de dados secundários, em especifico um relatório elaborado e emitido pelo Departamento de Recrutamento e Seleção de Pessoal da Administração Pública de Portugal, publicado no ano de 2006, dois anos após o desenvolvimento do modelo de gestão por competências nesta organização. A partir deste relatório, foi conduzida uma análise a fim de que fosse possível verificar pontos criticos do modelo de gestão por competências da Administração Pública de Portugal diante do ciclo interligado de legitimação e validação qualitativa de modelos de competências utilizado como referência. Na sequência, dá-se início as discussões teóricas.

\section{Ciclo Interligado de Legitimação e Validação Qualitativa de Modelos de CoMPETÊNCIAS}

Mishler (1990) defende que pesquisas quantitativas buscam por estados de validade enquanto pesquisas qualitativas interessam-se por processos de validação, bem por isso define a "validação como construção social do conhecimento" (MISHLER, 1990, p. 417). Ao basear-se nos trabalhos de Lyotard (1984), Lather (1993) propõe a noção de uma validade paralógica ou neopragmática, por meio da qual o conhecimento científico não tem a incumbência de buscar uma correspondência com a realidade, mas sim de descobrir diferenças e contradições presentes na tensão existente entre essas diferenças. Por tais constatações Lather (1993) considera que a validade do conhecimento é especificada pela resolução da questão sobre até que ponto os objetivos de investigação foram atingidos. Hammersley (1992), em consonância aos estudos de Mishler (1990), ratifica que em pesquisas qualitativas a realidade torna-se acessível por meio de diferentes perspectivas envoltas aos fenômenos investigados, logo, tais pesquisas, no intuito de descobrir fragilidades no objeto estudado, visam a apresentar a realidade estudada e a não reproduzi-la, bem por isso, o processo de validação em procedimentos metodológicos qualitativos alicerçam-se em pilares que intentam apresentar o que ele denomina de "realismo sutil".

Essas considerações a respeito do termo "validação' foram apresentadas a fim de que seu entendimento fique coerente para com o contexto deste artigo, o qual foi desenvolvido por uma abordagem qualitativa e com o objetivo de analisar um modelo de gestão por competências a partir do ciclo interligado de legitimação e validação qualitativa. Em relação à consolidação e à validação dos modelos de competências, alguns trabalhos mais relevantes têm sido amplamente discutidos, tais como o de Shippmann et al. (2000) que propõe uma escala de dez níveis que classifica o rigor de modelos de competências. Esta escala envolve a efetividade do método de coleta de dados, os descritores de desenvolvimento, os procedimentos e os padrões de qualidade, a ligação do modelo com a estratégia do negócio e os procedimentos de validação e documentação (SHIPPMANN et al., 2000). Percebe-se, assim, que existem muitas questões a serem analisadas antes de se considerar um modelo como válido e mais ou menos benéfico para a organização.

Sparrow (1995) salienta que um grande problema no uso de modelos de competências é a falta de um entendimento comum do que realmente significa a competência. Isso tem levado muitas organizações a trabalharem com modelos mesclados ou integrados que se tornam verdadeiros campos de 'areia movediça'. Neste artigo, compreende-se que competências - a partir de definições extraídas da abordagem comportamental da escola norte-americana - sejam adequadamente definidas como o conjunto de características responsáveis por desempenhos individuais diferenciados. A gestão por competências é uma gestão estratégica que se incumbe de analisar a capacitação da organização como um todo (MARKUS; COOPER-THOMAS; ALLPRESS, 2005; BOYATZIS, 1982; SPENCER; SPENCER, 2003). O modelo de competências é o instrumento de medida utilizado na gestão por competências para operacionalizar e descrever as competências. (MILLS et al., 2002; RUANO, 2003; CARBONE, 2005)

Mediante as diversas vantagens abordadas pelos defensores de modelos de competências, surge a questão: como instalar ou conceber um modelo de competências válido na organização? De acordo com Smith (2008), o modelo deve apresentar uma definição operacional para cada competência e subcompetência (recursos), com seus respectivos indicadores de performances e padrões de análise e medidas de desempenho esperados. Dalton (1997) salienta que 
um modelo de competências deve garantir que os funcionários cobrados por desempenhar determinados comportamentos esperados tenham conhecimento das competências requeridas para se chegar a tal denominador.

Em síntese, compreende-se por um modelo de competências válido aquele que possui uma clara descrição sobre a hierarquização entre competências e subcompetências específicas para cada um dos espaços ocupacionais participados pelos diferentes indivíduos inseridos em um mesmo contexto de gestão. Em um modelo válido, a organização possui a capacidade de identificar as competências necessárias de serem desenvolvidas e aprimoradas em prol de que seus respectivos objetivos estratégicos sejam alcançados. Essas competências são discutidas e disseminadas em cada uma das áreas da empresa, para que assim os gestores e os demais funcionários adquiram uma noção comum sobre o significado de cada competência, além de estarem cientes de como tais competencias serão mensuradas e avaliadas pela organização. Um modelo de competências é válido, portanto, quando possui uma linguagem comum em diferentes níveis estratégicos junto à organização que o ampara, situação que permite qualidade e agilidade nos processos de avaliação, implantação e aprimoramento do mesmo. (McLAGAN, 1997; SHIPPMANN et al., 2000; SPARROW, 1995; MARKUS; COOPER-THOMAS; ALLPRESS, 2005; SMITH, 2008)

As etapas do processo de verificação da validade de um modelo de competências estruturado por Munck, Munck e Borim-de-Souza (2011) são apresentadas no Quadro 1.

Ao se escolher um modelo de competências deve-se antes, durante e depois buscar respostas para as seguintes questões: a competência pode ser operacionalizada de forma a possibilitar sua observação $e$ medição? O indicador de um traço ou característica individual mede realmente aquilo a que pretende? Quais os critérios utilizados para validar as proposições do modelo junto a seus usuários? A que processos o modelo de competências estará relacionado, pessoas, estratégia, resultados? Em que momentos? Com que objetivos?

Essas questões, juntamente às discussões teóricas realizadas, foram organizadas e sintetizadas de forma a permitir a proposição de um ciclo interligado de legitimação e validação qualitativa de modelos de competências, demonstrado na Figura 1.

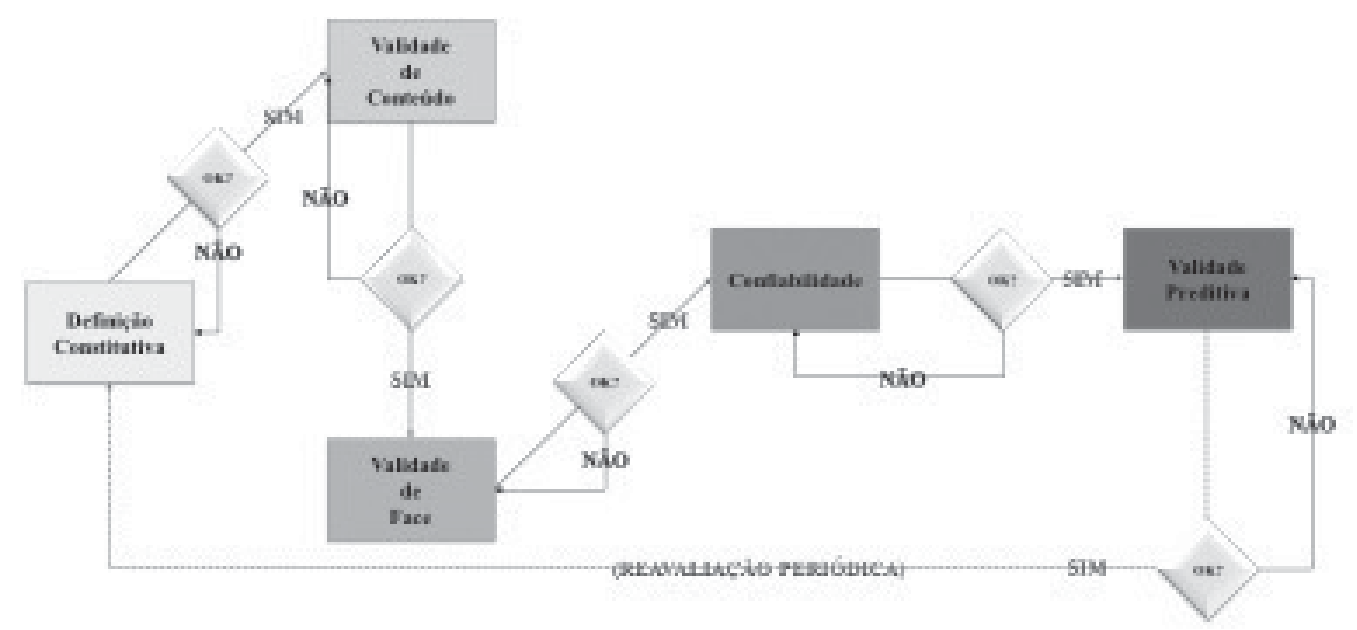

Figura 1: Ciclo interligado de legitimação e validação qualitativa de modelos de competências Fonte: Adaptada de Munck, Munck e Borim-de-Souza (2011)

A Figura 1 indica que o ciclo interligado de legitimação e validação qualitativa de modelos de competências possui começo e fim e pode ser reiniciado a qualquer momento mediante demandas de reavaliação do mesmo. Por essa inferência acredita-se que o construto em questão, a competência, apenas será validado se forem identificadas as diferentes concepções a respeito dele no interior da organização (definição constitutiva). 


\begin{tabular}{|c|c|c|}
\hline \multirow{3}{*}{\multicolumn{2}{|c|}{ 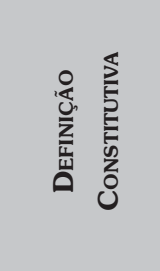 }} & $\begin{array}{l}\text { Significado: indica a definição de competência para o contexto analisado, esclarece o processo por meio do qual tal } \\
\text { significado foi acatado como o mais coerente e apresenta meios de operacionalização de cada uma das competências } \\
\text { inseridas ao modelo investigado, a fim de que observações e avaliações possam ser realizadas. }\end{array}$ \\
\hline & & bjetivos: verificar se o indicador de um traço ou característica individual mede realmente aquilo que pretende. \\
\hline & & $\begin{array}{l}\text { ificuldades: a competência é uma construção psicológica, possível de ser conceituada de formas diferentes por } \\
\text { squisadores e consultores. }\end{array}$ \\
\hline \multirow{9}{*}{ 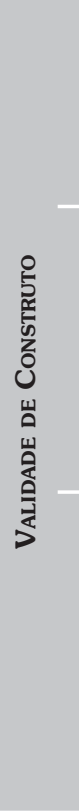 } & \multirow{3}{*}{ 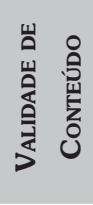 } & Significado: indica que os descritores de competências compõem uma amostra representativa do universo de interesse. \\
\hline & & Objetivos: testar se os descritores de competências compõem uma amostra representativa do universo disponível para tal. \\
\hline & & $\begin{array}{l}\text { Dificuldades: encontrar experts na abordagem conceitual adotada, bem como na cultura organizacional quando da } \\
\text { implantação de modelos de competências. }\end{array}$ \\
\hline & \multirow{3}{*}{ 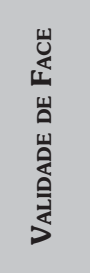 } & $\begin{array}{l}\text { Significado: indica que as competências exigidas pela organização, quando analisadas pelos funcionários que as precisam } \\
\text { desenvolver, são consideradas como apropriadas. }\end{array}$ \\
\hline & & $\begin{array}{l}\text { Objetivos: avaliar se a própria descrição das competências, em si, apresenta significados comuns e apropriados na visão } \\
\text { dos funcionários. }\end{array}$ \\
\hline & & $\begin{array}{l}\text { Dificuldades: as descrições e avaliações, por serem dependentes da cultura organizacional, possuem alto teor de } \\
\text { subjetividade. }\end{array}$ \\
\hline & \multirow{3}{*}{ 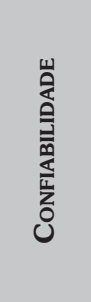 } & Significado: indica o nível de precisão com que as competências são mensuradas. \\
\hline & & $\begin{array}{l}\text { Objetivos: questionar se há precisão na medição das competências, principalmente para referenciar ganhos financeiros } \\
\text { e promoções. }\end{array}$ \\
\hline & & $\begin{array}{l}\text { Dificuldades: muitas competências, especialmente aquelas genéricas relacionadas ao desempenho de contexto, são } \\
\text { definidas em termos muito amplos e com poucos indicadores objetivos de desempenho. É improvável que a avaliação } \\
\text { precisa seja possível, mas validar a confiabilidade é um caminho, pois sua falta tem implicações nas percepções de justiça } \\
\text { organizacional. }\end{array}$ \\
\hline \multirow{3}{*}{\multicolumn{2}{|c|}{ 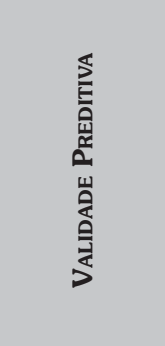 }} & Significado: indica se as competências contribuem para melhorias no desempenho individual e/ou organizacional. \\
\hline & & $\begin{array}{l}\text { Objetivos: analisar se as competências desenvolvidas contribuem para melhores desempenhos individuais e } \\
\text { organizacionais. Caso não, a seguinte pergunta deve ser respondida: por que investir em modelos de alta complexidade } \\
\text { e de alto custo gerencial? }\end{array}$ \\
\hline & & $\begin{array}{l}\text { Dificuldades: existem incongruências entre o que é medido, o que se queria medir e o que se deveria medir nas } \\
\text { organizações. Um sistema de medição eficaz deve atender a dois requisitos: melhora no processo decisório em gestão de } \\
\text { pessoas e geração de informações sobre a melhor alocação de recursos. Caso não, é preciso ceder espaço para a constante } \\
\text { confusão estabelecida entre competências e desempenho nas funções desempenhadas pelo indivíduo na organização. }\end{array}$ \\
\hline
\end{tabular}

Quadro 1: Descrição das etapas do processo de verificação da validade de um modelo de competências

Fonte: Adaptado de Munck, Munck e Borim-de-Souza (2011)

Essas divergências devem ser submetidas à análise de especialistas e de personagens organizacionais estratégicas, a fim de que, em conjunto, por serem conhecedores do arcabouço teórico-empírico que rege o modelo na empresa e da cultura organizacional imperante, possam sanar e corrigir tais debilidades, para que assim conquiste-se a primeira evidência deste processo de validação, a coerência conceitual e comunicativa a respeito do modelo em análise.

O estabelecimento de um conceito comum caracterizado por sua coerência junto aos diversos atores organizacionais indica a conquista da validade de conteúdo e da validade de face. Esse conceito, além de coerente, precisa ser divulgado e disseminado no ambiente organizacional que sustenta o modelo de competências em prol de que uma segunda evidência seja alcançada. Tal evidência é responsável por indicar a confiabilidade do modelo analisado, ou seja, a assimilação dessas discussões por parte dos principais sujeitos envolvidos em processos que dependem do modelo analisado. 
Assim que esses temas forem assimilados, existe a necessidade de avaliar as atitudes tomadas em favor de tal resultado, ou seja, ocorre o interesse de se contemplar as consequências e a efetiva contribuição de cada ação de gestão tomada com vistas a assimilação dos conceitos vinculados ao modelo de competências. Caso as consequências não sejam prejudiciais e a eficácia de tais decisões seja confirmada junto aos gestores e funcionários, diz-se que o modelo de competências, possui uma validade preditiva confirmada pela acurácia das ações tomadas em prol da assimilação de tal fenômeno. A acurácia, de acordo com Munck (2005), indicará que os procedimentos organizacionais tomados em prol da assimilação de conceitos relacionados ao modelo de competências conquistaram a plenitude dos resultados esperados para cada um deles.

O sucesso advindo dos procedimentos supramencionados não identificará a perfeição do modelo de competências, mas sim denunciará suas falhas mais relevantes. Mediante tal descoberta, a organização pesquisará por padrões de gestão que permitam a ela, cada vez mais, relacionar competências e resultados organizacionais por meio de boas práticas inteiramente relacionadas com suas estratégias. Caso essas constatações alcancem reconhecimento junto ao corpo gestor da empresa e o mesmo opte por reavaliar o modelo após a conclusão da necessidade de se proceder com lapidações imprescindíveis, admoesta-se que o aperfeiçoamento do modelo poderá ser observado, por meio de reavaliações periódicas.

Caso uma das etapas, conforme é ilustrado na Figura 1, não seja plenamente constatada ao longo do processo de observação do ciclo de legitimação $e$ validação qualitativa proposto, ela não pode ser ignorada, mas sim aperfeiçoada, no entanto, tal decisão apenas deve ocorrer mediante um consenso sobre a necessidade de se revisar qualquer etapa anterior. Por exemplo, se não houver validade de conteúdo, não há razão de se avançar para a avaliação da validade de face, se não forem comprovadas as validades de conteúdo e de face entende-se que não se deva caminhar para a avaliação da confiabilidade do modelo, $e$ assim por diante.

A Figura 1 e as discussões que a seguiram servem para demonstrar como as etapas selecionadas dos caminhos metodológicos percorridos na pesquisa de Munck, Munck e Borim-de-Souza (2011) podem confluir em um ciclo interligado de legitimação $e$ validação qualitativa de modelos de competências em organizações interessadas em ter tal ferramenta não somente como mais um mero instrumento de gestão, mas também, e principalmente, como um auxiliador nos processos organizacionais que intentam alcançar os objetivos estratégicos estabelecidos. Sendo assim, segue-se para a apresentação do modelo de gestão de competências adotado pela Administração Pública de Portugal, objeto de estudo deste artigo, que posteriormente será analisado sob a lógica do ciclo interligado de legitimação e validação qualitativa de modelos de competências apresentado neste tópico.

\section{O Modelo de Gestão por Competências da Administração Pública de Portugal}

A partir da aplicação de estudos de follow-up (acompanhamento) em grupos profissionais mais frequentemente avaliados no Departamento de Recrutamento e Seleção de Pessoal da Administração Pública de Portugal, foi constatada a oportunidade de implantação de um modelo de gestão por competências na Administração Pública de Portugal, por uma equipe de psicólogos do Departamento de Recrutamento e Seleção de Pessoal (DGAP, 2006). Depois da implantação, elaborou-se um relatório o qual expõe o desenvolvimento e a aplicação de uma metodologia objetiva e estruturada, que teve por objetivo introduzir maior rigor no diagnóstico das necessidades e na avaliação dos resultados da formação profissional. Tal documento apresenta um roteiro detalhado para a aplicação desta metodologia, além de divulgar a aplicação prática em três grupos profissionais pertencentes aos setores da Segurança e da Saúde da Administração Pública de Portugal. O relatório foi então utilizado com vistas a contextualizar e a atingir o modelo de gestão de competências utilizado pela Administração Pública de Portugal, a fim de avaliá-lo conforme o ciclo interligado de legitimação e validação qualitativa, exposto no tópico anterior.

O conceito de competência de referência adotado pelo DGAP (2006) é o definido por Spencer e Spencer (1993), em que 
[...] competência é uma característica pessoal subjacente, bastante estável e profunda, de personalidade de uma pessoa, que está relacionada de forma causal com um desempenho eficaz e/ou superior, numa função ou situação determinada. (DGAP, 2006, p. 21)

Ainda, com base nos mesmos autores, são adotados cinco tipos de características que definem uma competência: motivação, traços pessoais e autoconceito - competências invisíveis, que são reveladas no comportamento; e conhecimento e perícias - competências visíveis, passíveis de observação direta. É referenciada também a categorização de Spencer e Spencer (1993) sobre as competências básicas (características essenciais que todos devem possuir a fim de serem minimamente eficazes no trabalho - conhecimentos, perícias básicas) e as competências diferenciadoras (distinguem as pessoas com desempenho de nível superior das que têm um desempenho de nível médio). Ao expor que a centralidade admitida para o relatório reside nas competências individuais, foi estabelecido o conceito adotado pelo DGAP (2006, p. 25) sobre as competências individuais:

Conjuntos de comportamentos que o indivíduo manifesta no exercício da sua atividade profissional, e que garantem um desempenho de sucesso. Tais comportamentos são observáveis e mensuráveis tornando possível uma avaliação mais objetiva e adaptada à realidade da função, com maior valor preditivo do sucesso do indivíduo no desempenho.

Em adição, cada competência deve conter sua designação, definição e operacionalização (identificação de comportamentos observáveis e avaliáveis). Essa definição ainda segue aos seguintes princípios: devem ser ancoradas comportamentalmente; devem ser observáveis; estar orientadas para o futuro; refletir a cultura organizacional; devem ser discretas e evitar ambiguidades; e serem dispostas em um número gerenciável, de seis a 12 competências individuais para cada função.

O relatório publicado pelo DGAP (2006) ainda aponta que uma hierarquização interna foi desenvolvida, em que se estabeleceram três níveis de competências: (1) competências essenciais - competências cujas presenças são imprescindíveis para um desempenho bem sucedido; (2) competências muito importantes - competências que não sendo imprescindíveis ainda asseguram um desempenho superior; e (3) competências importantes - competências cujas presenças representam uma real mais-valia para a organização.

Em relação ao modelo de gestão por competências, o DGAP (2006) utiliza-se da abordagem de North e Reinhardt (2003), na qual é afirmado que por meio de um modelo integrado de gestão por competências é possível sincronizar os objetivos individuais com os objetivos estratégicos da organização. Dessa forma, é concebido pelo DGAP (2006) que os componentes tradicionais da identidade de uma organização (missão, visão e valores) são traduzidos em linguagem comportamental e utilizados para selecionar, avaliar, formar ou desenvolver pessoas.

Para a definição das competências, o modelo metodológico desenvolvido pelo DGAP (2006) inicia-se com o estudo das funções, o qual foi realizado por meio de uma perspectiva multimétodo. Partiu-se da identificação dos objetivos e das boas práticas de cada função, a partir dos comportamentos dos profissionais os quais foram captados em de entrevistas de visão (com gestores da alta cúpula), entrevistas com dirigentes intermediários e entrevistas com os ocupantes da função. As entrevistas de visão foram realizadas por entender-se que elas permitem justamente obter a visão de quem está centrado nas prioridades, de quem define objetivos de curto e longo prazo, com uma perspectiva de desenvolvimento e de futuro. Já as entrevistas com dirigentes intermediários foram realizadas em virtude da possibilidade de conseguir informações sobre a função sob a ótica de quem dirige e tem uma clara opinião sobre a forma como as tarefas devem ser realizadas, distinguindo facilmente os bons dos maus desempenhos. Estas últimas entrevistas foram complementadas pela técnica da matriz de construtos e por questionários de análise de trabalho. Por fim, foram feitas entrevistas com os titulares das funções por facilitarem a identificação de tarefas que compõem cada função, as responsabilidades associadas $e$ as dificuldades sentidas na execução diária da mesma. Nestas entrevistas foi utilizada também a técnica de incidentes críticos, proposta por Flanagan (1954), a qual é considerada muito útil na clarificação das funções.

Após a sistematização das informações angariadas nas entrevistas, procedeu-se a uma análise de conteúdo que agrupou tais informações em categorias. 
A essa categorização, seguiu-se o perfil de competências, que, em consonância ao referencial teórico adotado, foi sistematizado por uma hierarquia de competências, distribuídas em três níveis de importância: essenciais, muito importantes e importantes. O perfil de competências, juntamente com os dados obtidos relativos à função, permitiu elaborar o perfil profissional. (DGAP, 2006)

Segundo o relatório do DGAP (2006), a elaboração prévia do perfil de competências permitiu que, no processo de recrutamento de pessoal da Administração Pública de Portugal fossem valorizados e divulgados os comportamentos identificados como determinantes de um desempenho de sucesso. Do mesmo modo, as metodologias de seleção devem ser apontadas em função das exigências e das competências avaliadas.

No processo de recrutamento de pessoal, foram exemplificadas práticas de sua execução, sem, contudo, demonstrar os resultados devido aos princípios de sigilo impostos ao DGAP. Para a escolha das técnicas de avaliação de competências, o DGAP (2006) teve como premissa elaborar uma matriz em que se cruzam as competências a serem avaliadas com os instrumentos considerados mais indicados para esse efeito, tais como provas situacionais, entrevista de avaliação de competências e questionários autodescritivos. Após a coleta de dados, eles foram integrados com a participação de todos os profissionais envolvidos na avaliação, com foco nas evidências comportamentais e na harmonização de perspectivas e critérios. Desse modo, foi possível traçar um perfil individual de desempenho comparável ao perfil de competências elaborado para a função. Essa análise evidenciou os pontos fortes e as necessidades de desenvolvimento, além de, por conseguinte, permitir a tomada de decisão sobre o real valor de cada indivíduo para a organização. (DGAP, 2006)

Conforme postulado pelo DGAP da Administração Pública de Portugal (2006), apenas como recomendações ainda não aplicadas até a publicação do relatório, a elaboração de um plano de formação profissional deve orientar-se para o desenvolvimento de competências. Nesse âmbito, a formação profissional prescinde de uma perspectiva macro, uma vez que sua missão é servir a uma população com especificidades geográficas, econômicas e socioculturais. Logo, torna-se indispensável a sensibilização dos novos profissionais para a deontologia e ética do serviço público, envolvimento sociocultural, e para as especificidades da organização e da função. De maneira geral, o desenvolvimento de competências técnicas deve ser feito por meio de treinos na utilização de equipamentos e materiais associados ao desempenho da função. Já as competências comportamentais devem ser desenvolvidas por meio de noções gerais sobre o comportamento humano e sobre a dinâmica das relações interpessoais, acompanhadas por treinamentos e experimentações em situações concretas. (DAGP, 2006)

Uma vez reconhecida a relação dinâmica das organizações e a necessidade permanente de reajustamento, foi admitido pelo DGAP (2006) que um dos instrumentos de alcance aos gestores deva ser a revisão periódica das competências dos perfis profissionais. Segundo o relatório emitido pelo DGAP (2006), as avaliações da formação e do desenvolvimento das competências individuais podem ser asseguradas por um instrumento que associe as competências a uma escala que permita ao avaliador definir em que grau o indivíduo atingiu os objetivos de desenvolvimento previamente identificados como desejáveis. Os métodos de avaliação e de classificação dos níveis de desenvolvimento atingidos deverão estar adaptados ao conteúdo em avaliação, bem como contextualizados ao exercício real da atividade profissional para os quais os indivíduos são preparados. Com base no perfil profissional e no diagnóstico de necessidades de desenvolvimento, deve ser possível elaborar um plano de formação inicial para qualquer função na Administração Pública de Portugal. (DGAP, 2006)

O DGAP (2006) ainda prevê que a avaliação da eficácia do modelo integrado de gestão por competências deve ser feito a partir da avaliação periódica da avaliação das competências no exercício efetivo da atividade profissional, haja vista delas dependem fortemente os resultados obtidos pela organização. Observa-se, assim, que a análise do gap entre o comportamento real e ideal é o foco deste modelo de avaliação de desempenho elaborado pelo DGAP (2006). A utilização periódica de instrumentos de avaliação assegura uma recolha sistemática de indicadores tanto destinados ao indivíduo, quanto à organização. Ao primeiro, permite a tomada de consciência das suas competências e necessidades de desenvolvimento, a decisão sobre investimentos na sua formação e a orientação de sua atividade profissional para novas áreas, tendo em vista 
as novas competências adquiridas. Já à segunda, é possibilitada a identificação de necessidades de formação, a redistribuição de recursos humanos e a redefinição de perfis de competências, quando necessário.

De acordo com o relatório publicado pelo DGAP (2006), o follow-up do exercício da função é concretizado a partir de questionários de avaliação de competências, destinados às chefias e aos titulares das funções. Tais questionários, baseados em comportamentos observáveis e mensuráveis, são exemplificativos da necessidade e possibilidade de avaliar competências com a utilização de linguagem comum entre os interlocutores $e$, consequentemente, com a redução de desigualdades e eventuais conflitos da situação de avaliação. Até o momento de publicação do relatório em análise, os questionários ainda não haviam sido aplicados, sendo esse o motivo da não divulgação dos resultados.
Após o desenvolvimento de uma metodologia objetiva que permite a gestão de pessoas baseada nas competências comportamentais, o modelo de gestão de competências desenvolvido pelo DGAP (2006) retratou, com aplicações práticas ou apenas no campo teórico, as vantagens de uma gestão de pessoas feita com base no modelo de competências em todas as suas fases, desde o recrutamento e a seleção, passando pela formação inicial ou em exercício, até a avaliação de desempenho. Em síntese, a Figura 2 ilustra o desenvolvimento do modelo de gestão por competências da Administração Pública de Portugal.

Apresentado o modelo de gestão por competências da Administração Pública de Portugal, a próxima seção irá contemplar a submissão desse modelo à análise por meio do ciclo interligado de validação, objetivo principal deste artigo.

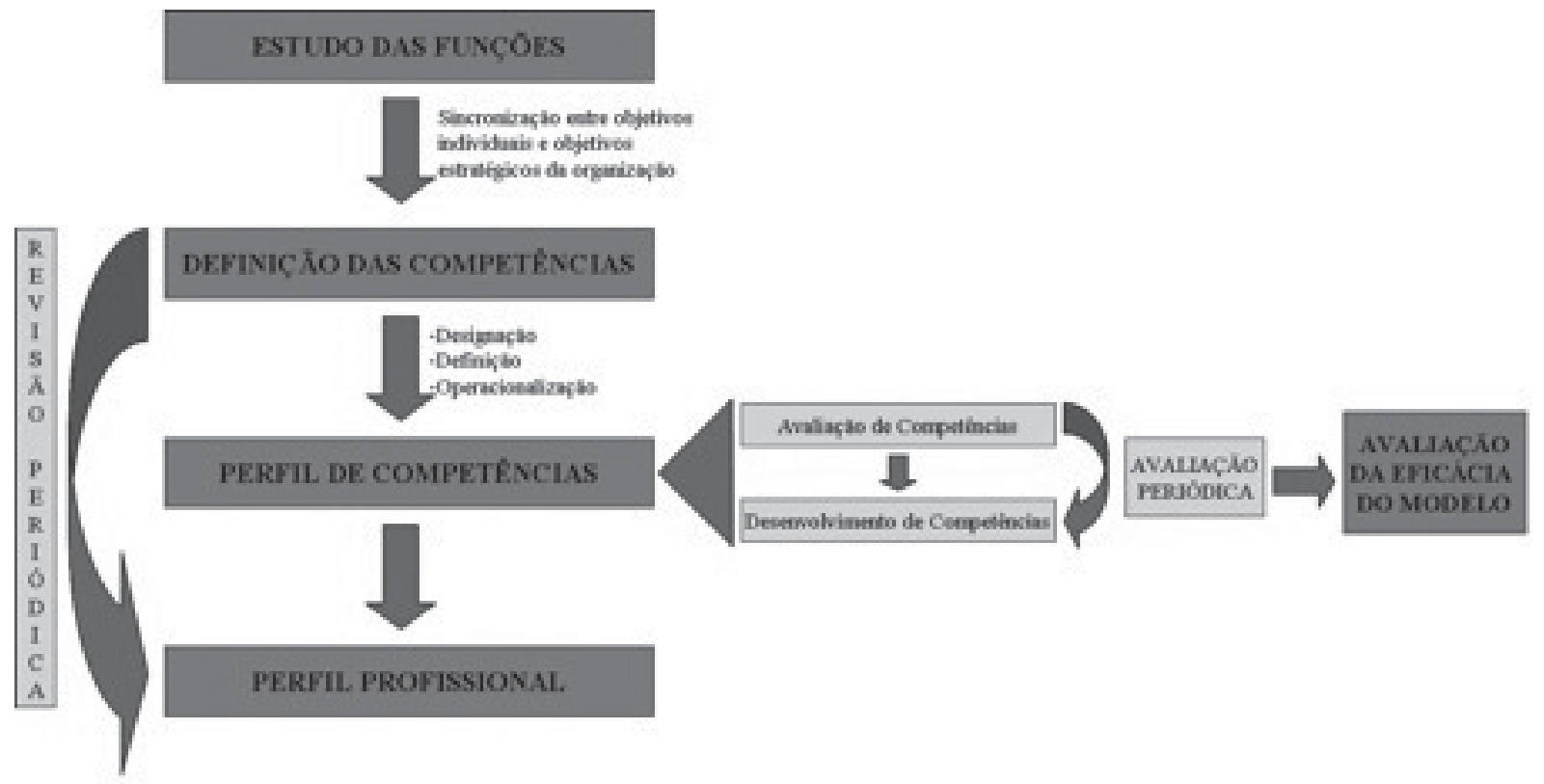

Figura 2: Modelo de gestão por competências da Administração Pública de Portugal Fonte: Adaptada de DGAEP (2006) 


\section{Análise do Modelo de Gestão Competências da Administração Pública de Portugal Por Meio do Ciclo Interligado de Legitimação E VALIDAÇÃO}

Considerando o objetivo principal da investigação, utilizou-se como base desta pesquisa a análise documental, no caso o relatório emitido pelo DGAP (2006) acerca da implantação de um modelo de gestão por competências na Administração Pública de Portugal. A partir da construção do ciclo interligado de legitimação e validação, foram descritas as categorias listadas no protocolo de coleta de dados, representado pelo Quadro 1, a fim de que a análise do relatório fosse delineada pelas informações da coluna 'o que verificar', extraídas de recomendações teóricas vinculadas a análises do processo de validação de modelos de competências, referenciadas no Tópico 3 deste artigo.

O Quadro 1 contempla, em síntese, um roteiro para coleta e análise dos dados segmentado pelas etapas indicadas por Munck, Munck e Borim-de-Souza (2011) no ciclo interligado de legitimação e validação qualitativa de modelos de competências ilustrado na Figura 1.

Desde já se esclarece que a proposição de um estudo que pretenda verificar a aplicação de processo de validação de modelos de competências utilizado pela Administração Pública de Portugal não está acompanhada pela intenção de gerar expectativas de que as organizações, públicas ou privadas, assumam intensamente as várias etapas do processo de validação contemplado no exercício metodológico adotado. É fato, $e$ os autores do presente artigo reconhecem, que as organizações, em particular as do setor público,

\begin{tabular}{|c|c|c|c|}
\hline \multicolumn{2}{|c|}{ Categorias } & VARIÁVEIS & O QUE VERIFICAR? \\
\hline 选 & 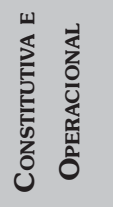 & $\begin{array}{l}\text { - Natureza do conceito } \\
\text { - Operacionalização do conceito } \\
\text { - Alinhamento/referência }\end{array}$ & $\begin{array}{l}\text { - As competências selecionadas para compor o modelo podem ser } \\
\text { operacionalizadas de forma a possibilitar sua observação e medição? } \\
\text { - A medida de uma característica ou traço individual mede o que se almejava } \\
\text { medir? }\end{array}$ \\
\hline \multirow{3}{*}{ 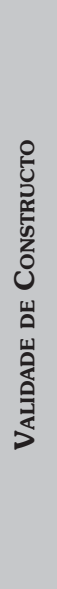 } & 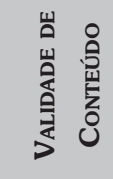 & $\begin{array}{l}\text { - Abrangência } \\
\text { - Representatividade } \\
\text { dos descritores }\end{array}$ & $\begin{array}{l}\text { - A própria descrição das competências selecionadas para constituir o modelo } \\
\text { apresenta significados comuns e apropriados? } \\
\text { - Os descritores de competências são uma amostra representativa do universo } \\
\text { disponível para tal? }\end{array}$ \\
\hline & 崖 & $\begin{array}{l}\text { - Abrangência } \\
\text { - Representatividade } \\
\text { dos descritores }\end{array}$ & $\begin{array}{l}\text { - A própria descrição das competências selecionadas para constituir o modelo } \\
\text { apresenta significados comuns e apropriados? } \\
\text { - Os descritores de competências são uma amostra representativa do universo } \\
\text { disponível para tal? }\end{array}$ \\
\hline & 崖 & $\begin{array}{l}\text { - Acurácia/precisão } \\
\text { - Confiabilidade } \\
\text { - Documentação }\end{array}$ & $\begin{array}{l}\text { - Há acurácia na avaliação das competências inseridas no modelo acatado pela } \\
\text { organização? } \\
\text { - Como ela é verificada e documentada? }\end{array}$ \\
\hline & 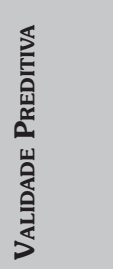 & $\begin{array}{l}\text { - Relação modelo/resultados } \\
\text { - Benefícios } \\
\text { - Ligação com objetivos e } \\
\text { estratégias organizacionais } \\
\text { - Revisão do modelo }\end{array}$ & $\begin{array}{l}\text { - O desenvolvimento das competências preconizadas pelo modelo promove o } \\
\text { alcance de resultados frente aos objetivos propostos? } \\
\text { - As competências que concedem forma ao modelo geram melhoria no } \\
\text { desempenho individual e/ou organizacional e outros benefícios? } \\
\text { - O modelo apresenta meios de integração com objetivos e metas organizacionais? } \\
\text { - O modelo orienta a gestão na tomada de decisão? } \\
\text { - Quais os critérios utilizados para revisões no modelo? }\end{array}$ \\
\hline
\end{tabular}

Quadro 1: Protocolo para coleta e análise de dados

Fonte: Adaptado de Munck, Munck e Borim-de-Souza (2011) 
enfrentam inúmeras limitações em seus roteiros cotidianos de gestão, os quais podem abalar ou fragilizar a efetiva aplicação do referido processo de validação, por isso, ressalta-se que não existe o interesse de constituir uma ideologia que cobre das organizações o mesmo rigor científico adotado pela academia. Mas, ainda que feitas tais considerações, as análises dos dados e as considerações finais foram redigidas com a indicação de críticas que visam ao aprimoramento da gestão das organizações e não a um distanciamento entre as comunidades científica e organizacional. Segue-se então à análise dos dados separada pelas etapas constituintes do ciclo.

\subsection{Definição Constitutiva e Operacional}

Em análise ao relatório emitido pelo DGAP (2006), foi possível observar que os conceitos utilizados pela organização, tanto acerca da definição de competências quanto do modelo de competências, são de natureza teórica, baseados principalmente nas contribuições de Spencer e Spencer (1993), Franco (2001), Flanagan (1954) e North e Reinhardt (2003). Identificaram-se evidências de que todo o processo de implantação do modelo de competências seguiu em conformidade com as referências teóricas adotadas. Acerca da variável referente à natureza do conceito, o modelo de gestão por competências da Administração Pública de Portugal, recebe a validação de definição constitutiva e operacional.

De acordo com a definição de competências individuais concebida pelo DGAP (2006), elas representam comportamentos observáveis e mensuráveis a fim de que possam ser avaliadas $e$ adaptadas à realidade de cada função. O princípio de que a definição das competências deve estar ancorada a comportamentos indica que sua designação seja capaz de compreender a maneira como os indivíduos desempenham tarefas específicas. Do mesmo modo, o princípio de que as competências devem ser observáveis deve garantir que tais comportamentos sejam passíveis de observação e avaliação. Presume-se, por essas indicações, que pelo menos em tese, as competencias constituintes do modelo de gestão desenvolvido pela Administração Pública de Portugal são passíveis de observação, mensuração e avaliação. Logo, por esta variável também se confere validade na definição constitutiva e operacional deste modelo.
Acrescenta-se ainda que, como exposto em seção anterior, a definição das competências, inicia-se com o estudo das funções, a qual foi realizada por meio de entrevistas de visão, entrevistas com dirigentes intermediários e entrevistas com os ocupantes da função. Em específico às entrevistas com os dirigentes intermediários, a aplicação de matrizes de constructos, permitiu que fossem angariados comportamentos, características e capacidades que, em uma próxima fase devem compor as definições das competências individuais. O relatório elaborado pelo DGAP (2006) revela que nesta etapa, o entrevistado foi conduzido a objetivar suas percepções, no sentido de definir claramente o significado do conceito. Tal procedimento justificou-se pelo fato de que os constructos indicados pelos entrevistados - comportamentos, características e capacidades - variam de pessoa para pessoa, de organização pra organização e de cultura para cultura. Dessa maneira, tanto a definição quanto a descrição das competências recebem maior objetividade e, novamente, é possível apontar a validade na definição constitutiva e operacional do modelo de gestão por competências da Administração Pública de Portugal.

\subsection{Validade de Constructo}

A validade de construto é composta pelas validades de conteúdo, de face e pela confiabilidade. Conforme indicações de Munck, Munck e Borim-de-Souza (2011), neste processo de validação, as três validades constituintes da validade de construto devem ser conferidas para que esta possa também ser verificada. $\mathrm{Na}$ sequência, as três validades são analisadas e ao final do tópico, é apresentada a síntese da análise sobre a o modelo de gestão em estudo.

\subsubsection{Validades de Conteúdo e de Face}

Foi citado anteriormente que o relatório publicado pelo DGAP (2006) divulgou a aplicação prática em três grupos profissionais pertencentes aos setores da Segurança e da Saúde da Administração Pública de Portugal. No relatório, constam os critérios da escolha destes grupos e algumas de suas características, entretanto, em momento algum foi esclarecida a população sobre a qual tais grupos foram selecionados. Por exemplo, no Grupo Profissional I, dois responsáveis 
participaram da entrevista de visão; quatro dirigentes intermediários foram entrevistados, a despeito de que apenas três responderam à matriz de constructos, sem nenhuma menção às razões para tal; e dezoito foram as entrevistas realizadas com os ocupantes dos cargos, das quais resultaram vinte e quatro incidentes críticos.

Observa-se que realizar afirmações sobre a representatividade dos descritores das competências definidas para o modelo de gestão em pauta é, de alguma forma, limitada pelo texto dúbio do relatório. Uma vez considerado que os participantes das entrevistas, portanto, os fomentadores das informações que definem as competências, constituem toda a população daquele setor, infere-se que as validades de conteúdo e de face são, por este critério, verificadas. Contudo, dada as limitações e as contradições de algumas informações à este respeito, deduz-se que tais grupos são, de fato, uma parcela de indivíduos que pertencem a mesma função de um mesmo setor. Sobre esta variável então, não é possível conferir a validade de conteúdo.

Dentre as entrevistas de visão, com dirigentes intermediários, e com os ocupantes da função, realmente importantes para o delineamento dos comportamentos que justificaram as competências individuais, parecem ser as entrevistas com os dirigentes intermediários $e$ com os ocupantes da função, haja vista as entrevistas de visão limitaram-se à caracterização institucional, ao conteúdo funcional e às condições gerais do exercício da função.

A utilização de várias matrizes de constructos em complemento às entrevistas com os dirigentes intermediários permitiu que fossem levantados comportamentos, características e capacidades que, na perspectiva do entrevistado, diferenciam desempenhos mais ou menos eficazes à determinada função. As entrevistas realizadas com os titulares das funções foram associadas à técnica de incidentes críticos, e possibilitaram a evidenciação de comportamentos particulares mobilizados na resolução dos incidentes relatados. Por meio do cruzamento de informações provenientes das entrevistas com dirigentes intermediários e com titulares das funções, chegou-se às categorias referentes às dimensões comportamentais relevantes para um desempenho de sucesso, ou seja, competências. Alocadas em perfis de competências, as descrições de cada uma delas também foi elaborada de acordo com as informações explicitadas nas entrevistas em questão.
O que se almeja esclarecer destas explanações é o fato de que as competências foram definidas e descritas em conformidade e de maneira contextualizada a cada função, segundo as visões de quem a supervisiona e de quem a executa. Dessa forma, tanto as definições quanto as descrições das competências integrantes do modelo de gestão adotado pela Administração Pública de Portugal apresentam significados comuns e apropriados ao contexto a que pertencem, portanto, é conferida a validade de face, sobre esse critério.

\subsubsection{Confiabilidade}

Conforme aponta o relatório do DGAP (2006), a avaliação das competências individuais são primordiais à Administração Pública de Portugal, não somente no processo de recrutamento e seleção de candidatos, mas também nos processos de formação e desenvolvimento de competências.

No processo de recrutamento e seleção, foi instituído pelo DGAP (2006) que a avaliação de competências implica a utilização de instrumentos que facilitem a manifestação de comportamentos em situações experimentais, semelhantes às situações profissionais reais, de modo que seja possível ao avaliador identificar a presença ou a ausência dos comportamentos adequados à função. Ainda, é necessária a elaboração de matrizes de avaliação, a fim de que seja registrada a relevância de cada instrumento para a avaliação de determinadas competências. A construção de técnicas à medida das competências também é basilar à medida que permite a contextualização de provas à especificidade situacional do desempenho da função, e entrevistas de avaliação de competências são fundamentais uma vez que é possível ao avaliador obter o máximo de informações sobre comportamentos associados às competências. A partir da integração das informações recolhidas, é traçado um perfil individual de desempenho comparável ao perfil de competências traçado para a função e, assim, são subsidiadas decisões futuras sobre aprovação ou eliminação do candidato.

Garantir uma formação eficaz passa por uma avaliação, também eficaz, dos seus resultados. Segundo o relatório do DGAP (2006), a avaliação da formação e do desenvolvimento poderá ser assegurada por um instrumento que associe as competências a uma escala que permita ao avaliador, após cálculos de frequência 
e representatividade das mesmas, definir em que grau o indivíduo atingiu os objetivos previamente identificados como desejáveis. É enfatizado ainda que os métodos de avaliação e de classificação dos níveis de formação e desenvolvimento atingidos deverão estar adaptados ao conteúdo em avaliação, bem como contextualizados ao exercício real da atividade profissional para os quais os indivíduos são preparados.

Por tantas peculiaridades e especificidades em instrumentos é métodos, admite-se que há um razoável nível de precisão com que as competências individuais são avaliadas, verificadas e documentadas, seja no processo de recrutamento e seleção de candidatos, seja no processo de formação e desenvolvimento de competências direcionados aos profissionais já em exercício na organização. Dessa forma, reconhece-se a confiabilidade na avaliação das competências inseridas no modelo de gestão por competências acatado pela Administração Pública de Portugal.

Contudo, ao investigar-se sobre a credibilidade do modelo em pauta em relação à avaliação orientada para premiações e punições, percebe-se que esta é uma questão não muito desenvolvida. Vale lembrar que o objetivo do critério de confiabilidade é questionar se há precisão na medição das competências, principalmente para referenciar ganhos financeiros e promoções. $\mathrm{O}$ que é enfatizado pelo relatório publicado pelo DGAP (2006) é o fato de que no processo de recrutamento e seleção, ou de formação e desenvolvimento de competências com características probatórias, no caso de o indivíduo possuir um resultado negativo, este será eliminado do processo. Por outro lado, resultados positivos que acarretem premiações financeiras ou promoções não são relatados, apenas o ingresso na organização no caso do processo de recrutamento e seleção. Sendo assim, por não atender completamente à este critério, não é possível conferir a confiabilidade ao modelo de gestão por competências da Administração Pública de Portugal.

\subsection{Validade Preditiva}

Ao buscar respostas sobre a capacidade do modelo de predizer resultados em conformidade aos objetivos propostos, encontrou-se um obstáculo ao alcance de tais análises: até o momento de publicação do documento em estudo, os questionários ainda não haviam sido aplicados, logo, não há registros da divulgação dos resultados. Dessa forma, o que podem ser apontados, são indicações feitas pelo relatório acerca de previsões e argumentações teóricas sobre determinados critérios da validade preditiva do modelo em questão.

Conforme consta no relatório emitido pelo DGAP (2006), a avaliação da eficácia dos resultados provenientes do modelo integrado de gestão por competências da Administração Pública de Portugal, deve ser feita a partir da avaliação periódica das competências no exercício da atividade profissional. Para tanto, foi estabelecido que esta avaliação se apoie em comportamentos concretos e apresente comparações entre o desempenho do indivíduo e as expectativas da organização. Esta avaliação é concretizada então a partir de questionários de avaliação de competências destinados às chefias e aos titulares das funções, elaborados a partir do perfil de competências. Considera-se que aos indivíduos, seja fomentada a tomada de consciência das suas competências e necessidades de desenvolvimento, a decisão sobre investimentos na sua formação e a orientação de sua atividade profissional, tendo em vista novas competências adquiridas. Já à organização, é esperado que sejam identificadas as necessidades de formação específicas, a redistribuição de recursos humanos e a redefinição de perfis de competências, quando necessário.

Percebe-se nestas primeiras arguições que, pelo menos em tese, há evidente expectativa de que melhorias sejam alcançadas a partir das competências que concedem forma ao modelo integrado de gestão por competências da Administração Pública de Portugal. No entanto, reforça-se que são apenas expectativas, logo, não há comprovação da validade preditiva neste critério.

A respeito da integração com os objetivos e metas organizacionais, é preciso considerar a magnitude de uma organização pública, bem como, as aplicações práticas expostas pelo relatório do DGAP (2006), nos setores de Segurança e Saúde. Como foi descrito anteriormente, os processos de formação inicial de competências prescindem de uma perspectiva macro, portanto, instituiu-se como indispensável a sensibilização dos novos profissionais para a deontologia e ética do serviço público, envolvimento sociocultural, e para as especificidades da organização e da função, 
por meio da transmissão de conteúdos. Além disso, viu-se que a definição das competências foi constituída também por informações provenientes de entrevistas de visão com dirigentes da alta hierarquia de um setor em específico, os quais por possuírem uma visão mais abrangente da organização e de seus objetivos, possibilitaram a convergência da definição das competências individuais com os propósitos da perspectiva organizacional.

Por essas afirmações, observa-se que há intenção $e$ indícios de integração entre o modelo de gestão por competências da Administração Pública de Portugal e os objetivos desta organização, contudo, novamente, tais evidências não foram ainda comprovadas empiricamente. Ademais, não há garantias de que meramente a transmissão de conteúdos relacionados à estrutura da organização e do serviço público faça que o indivíduo situe-se e desenvolva-se de forma ativa em relação aos objetivos e resultados desejados pela organização.

No que tange à orientação do modelo de gestão à tomada de decisão, as prováveis inferências também se situam no âmbito teórico. Foi exposto que, basicamente, a gestão por competências é provável a impactar das decisões referentes aos processos de recrutamento e seleção e de demissão, sem que, contudo, fossem explicitadas as formas de ocorrência desta última. Segundo Mills et al. (2002), o modelo precisa ser aceito junto à organização não como um mero instrumento de gestão, mas como um auxiliador nos processos estratégicos, no entanto, parece que à Administração Pública de Portugal, a gestão do modelo por competências perpassa apenas no que tange aos assuntos relacionados à gestão de pessoas, e não à organização como um todo, portanto, não atinge a validade preditiva neste critério.

Por fim, sobre os critérios utilizados para revisões no modelo, o documento em análise enfatizou em diversos momentos do texto, a periodicidade com que devem ser reavaliadas as competências constantes dos perfis profissionais das funções, bem como os instrumentos de avaliação decorrentes. Apesar de salientado, esse é o único critério apontado pelo DGAP (2006) para revisões do modelo e, ainda, não foi indicada uma delimitação temporal na qual esta avaliação periódica deva ocorrer. Por ser um único critério e conter falhas em sua designação, considera-se que aqui a validade preditiva também não é alcançada.

A análise do modelo de gestão integrada por competências desenvolvida pela Administração Pública de Portugal à luz do ciclo interligado de legitimação e validação qualitativa de modelos de competências permitiu identificar pontos críticos no modelo em questão. A Figura 3 esclarece a interposição entre o modelo de gestão em estudo com o ciclo interligado de legitimação e validação qualitativa.

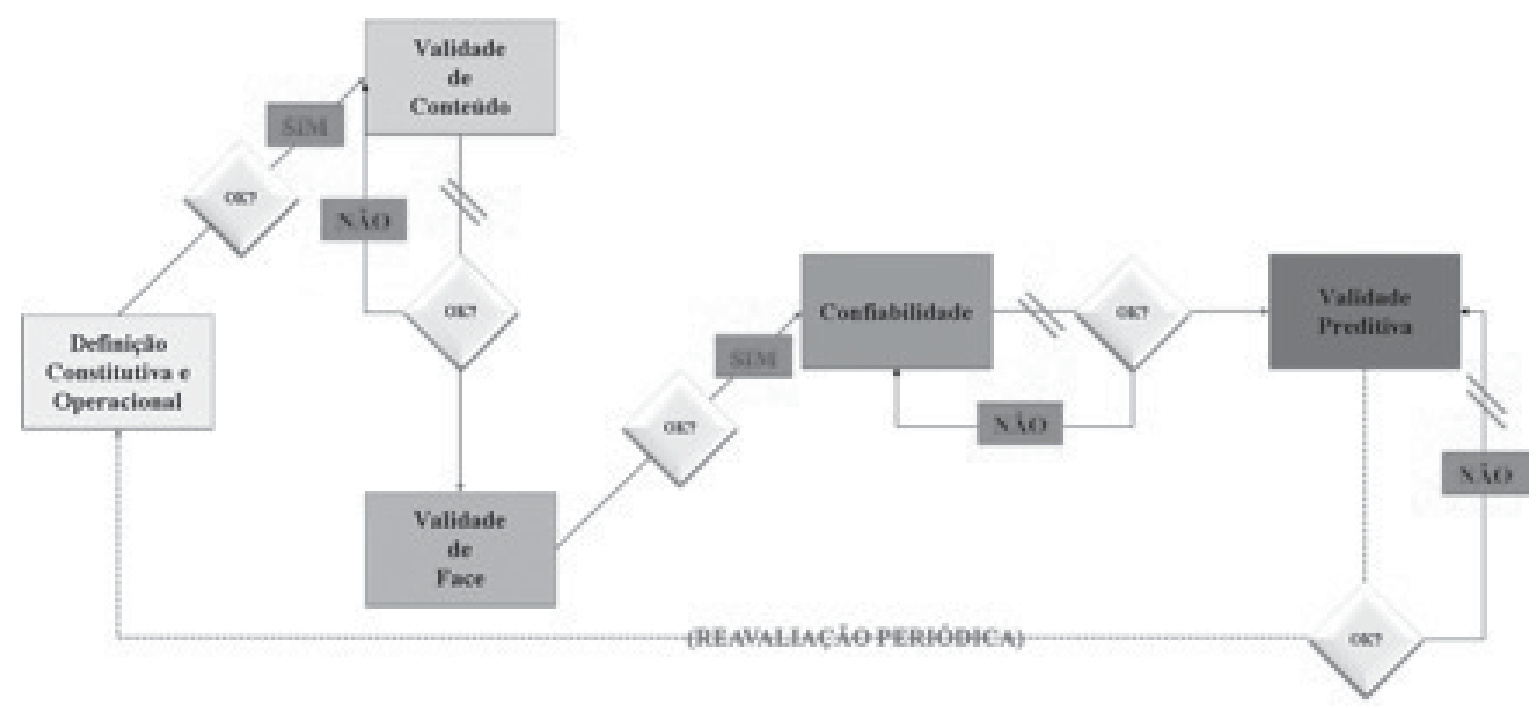

Figura 3: Análise do modelo de gestão por competências da Administração Pública de Portugal a partir do ciclo interligado de legitimação e validação qualitativa de modelos de competências

Fonte: Elaborada pelos autores deste artigo 
A Figura 3 apresenta, de modo sintético, a análise descrita neste tópico. Foram destacados na cor alaranjada os resultados verificados, convergências (sim) e divergências (não), entre o modelo em estudo e o ciclo proposto, em que as representações das divergências são acompanhados por dois traços, os quais apontam quebras no ciclo interligado de legitimação e validação de modelos de competências.

Em relação à validade sobre as definições constitutiva e operacional, foi exposto que o modelo integrado de gestão por competências da Administração Pública de Portugal está em conformidade com o ciclo interligado. Passa-se para a próxima etapa, a validade de constructo, na qual sua primeira análise concerne à validade de conteúdo que, a partir das averiguações apontadas, não é auferida ao modelo de Portugal. A validade de face, por outro lado, confere ao modelo de Portugal, o que não é o mesmo caso da última etapa da validade de constructo, a verificação da confiabilidade. Por fim, também não foi conferida a validade preditiva ao modelo de gestão por competências da Administração Pública de Portugal.

Pelas considerações teóricas vistas sobre o ciclo interligado, caso uma de suas etapas não seja plenamente constatada ao longo do processo, ela não pode ser ignorada, mas sim aperfeiçoada. Assim, não seria pertinente ao modelo de gestão por competências da Administração Pública de Portugal seguir em frente com o desenvolvimento e aplicação deste modelo já que a sua validade de conteúdo não foi comprovada. Tal fato pode significar erros no modelo como um todo, principalmente nas variáveis que compõem a validade de face, uma vez que sua elaboração seguiu com base em critérios inválidos sobre o seu conteúdo. Esta pode ser uma das razões pelas quais, inclusive, não foram apontadas a confiabilidade $e$ a validade preditiva do modelo em questão.

\section{Considerações Finais, Sugestões de Estudos Futuros e Implicações para}

\section{a Administração}

O presente artigo foi desenvolvido com o objetivo principal de analisar o modelo de gestão por competências da Administração Pública de Portugal, desenvolvido pelo Departamento de Recrutamento e Seleção de Pessoal, por meio do ciclo interligado de legitimação e validação qualitativa de modelos de competências.

Como resultado da análise, foi exposto que os conceitos de competências adotados no modelo da Administração Pública de Portugal foram desenvolvidos a partir de bases científicas e de modo que a sua operacionalização fosse viável, sendo então possibilitadas sua observação e medição. Em outras palavras, nesta primeira etapa de validação e legitimação, ao modelo de gestão por competências em análise é concedida a validade de definição constitutiva e operacional.

Todavia, ao partir-se para a segunda etapa, a conferência da validade de conteúdo, esta não pode ser comprovada, pois, se inferiu que os descritores de competências não eram suficientemente uma amostra representativa do universo de interesse do modelo. Já neste momento, havia necessidade de revisão do modelo em questão, para que fossem corrigidos os possíveis erros que pudessem podem circundá-lo por completo, uma vez que a validade de conteúdo constitui variáveis inválidas, sobre as quais o mesmo foi desenvolvido.

Ainda assim, as observações feitas sobre a terceira etapa, a validação de face, foram positivas, considerou-se que a própria descrição das competências selecionadas para constituir o modelo apresenta significados comuns e apropriados. Porém, se foram constituídas a partir de uma amostra não representativa de participantes, a validade de face pode ser comprometida.

Em consideração à terceira etapa, a confiabilidade, verificou-se que há precisão na medição das competências, no entanto, não há relação desta para a referência de ganhos financeiros e promoções. Logo, esta etapa não é comprovada. Vale destacar que, ao considerar a fragilidade das variáveis componentes da validade de face, por terem sido desenvolvidas sob a base restrita da validade de conteúdo, a confiabilidade pode também estar limitada se os métodos de mensuração foram elaborados conforme as competências de uma amostra não representativa.

Por fim, não foi comprovada também a validade preditiva, uma vez que há apenas expectativas de cumprimento de suas variáveis, como a integração entre o modelo de gestão por competências da Administração Pública de Portugal e os objetivos desta organização e a contribuição do referido modelo para melhores 
desempenhos individuais e organizacionais, averiguados a partir de avaliações individuais, organizacionais e do próprio modelo em si. Percebe-se que, mesmo que tais avaliações tivessem sido realizadas, seus resultados provavelmente não seriam condizentes com a realidade, em virtude de serem conduzidas a partir de bases não validadas.

O que se observa como consequência é um "efeito cascata" de invalidações e prováveis fragilidades a que o modelo de gestão por competências da Administração Pública de Portugal está submetido. Pelas considerações teóricas vistas sobre o ciclo interligado de legitimação e validação qualitativa utilizado para analisar o modelo em pauta, caso uma de suas etapas não seja plenamente constatada ao longo do processo, ela não pode ser ignorada, mas sim aperfeiçoada. Assim, não seria pertinente ao modelo de gestão por competências da Administração Pública de Portugal seguir em frente com o desenvolvimento e aplicação deste modelo já que a sua validade de conteúdo não foi comprovada.

A análise realizada a partir do ciclo interligado de legitimação e validação qualitativa de modelos de competências, e a decorrente identificação de pontos críticos, não intencionou identificar a perfeição ou imperfeição do modelo de competências de Portugal, mas sim verificar suas possiveis falhas mais relevantes. Mediante os resultados apresentados, a Administração Pública de Portugal poderá buscar padrões de gestão que permitam a ela, cada vez mais, relacionar competências e resultados organizacionais por meio de boas práticas inteiramente relacionadas com suas estratégias.

Para tanto, um dos caminhos a ser seguido é a submissão das divergências aqui apontadas à análise de especialistas e de personagens organizacionais estratégicas, a fim de que possam ser sanadas e corrigidas, para que assim conquiste-se a validação de conteúdo e sejam revistas as variáveis que compõem a validade de face e, por conseguinte, a confiabilidade e a validade preditiva possam ser verificadas comprovadamente.

Em seu âmbito, o presente artigo identificou pontos que precisam ser enfatizados bem como discutiu questões centrais no que se refere à implantação $e$ validação de modelos de competências. Como avanço principal, destaca-se a proposição de um caminho que visa não somente a validar uma competência ou lista de competências, mas o modelo como um todo.
A verificação das etapas de validação, em um ciclo contínuo, permite o refinamento do modelo ante as atuais e novas exigências conceituais, bem como as demandas organizacionais. Sendo assim, como implicações para a gestão, este estudo visa a possibilitar aos gestores um instrumento de análise orientadora e de avaliação, à medida que a aplicação do modelo aqui apresentado poderá fornecer informações que direcionarão a busca por melhores práticas na gestão por competências.

Retoma-se que objetivo principal deste artigo limitou-se a evidenciar possíveis pontos convergentes e divergentes entre o modelo de gestão por competências estudado e o ciclo interligado de legitimação e validação. Fica claro, portanto, que não houve interesse de realizar ou propor intervenções empíricas. Contudo, a realização de pesquisas empíricas é sugerida uma vez que devam trazer contribuições acadêmicas ao vislumbrar novas aplicações, correções, e subsídios a este estudo, bem como orientar e iniciar novas pesquisas. Recomenda-se que sejam realizadas pesquisas empíricas em outros órgãos públicos do mesmo país ou até mesmo de outra origem para que uma análise comparativa possa ser realizada, de forma a avançar nas considerações deste artigo.

\section{REFERÊNCIAS}

\section{BOYATZIS, R. E. The competent management: a} model for effective performance. New York: John Wiley, 1982.

CARBONE, P. P. Gestão por competência e gestão do conhecimento. Rio de Janeiro: FGV, 2005.

DALTON, M. Are competency models a waste? Training and Development, United States of America, v. 51, n. 10, p. 46-49, 1997.

DGAP - Departamento de Recrutamento e selecção de pessoal, Núcleo de Psicologia. Avaliação e desenvolvimento de competências na administração pública. Lisboa, 2006.

DREJER, A. Strategic management and core

competencies. Quorumbooks: USA, 2002.

DUTRA, J. S. Competências. São Paulo: Atlas, 2004. 
FLANAGAN, J. C. The critical incident technique.

Psychological Bulletin, Pittsburgh, v. 51, n. 4, p. 327358, 1954.

\section{FLEURY, A.; FLEURY, M. T. L. Estratégias}

empresariais e formação de competências: um quebra-cabeça caleidoscópico da indústria brasileira.

3. ed. São Paulo: Atlas, 2008.

FLICK, U. Introdução à pesquisa qualitativa. 3. ed. Porto Alegre: Artmed, 2009.

HAIR JR., J. F. et al. Fundamentos de métodos de pesquisa em administração. Porto Alegre: Bookman, 2005.

HAMMERSLEY, M. What's wrong with Ethnography? London: Routledge, 1992.

KIRK, J. L.; MILLER, M. Reliability and validity in qualitative research. Beverly Hills: SAGE, 1986.

KOCHANSKI, J. Competency-based management. Training and Development, United States of America, v. 51, n. 10, p. 41-44, 1997.

LATHER, P. Fertile obsession: validity after poststructuralism. Sociological Quarterly, Iowa City, v. 35, p. 673-693, 1993.

LYOTARD, J. F. The postmodern condition: a report on knowledge. Manchester: Manchester University Press, 1984.

MARKUS, L. H.; COOPER-THOMAS, H. D.; ALLPRESS, K. N. Confounded by competencies? An evaluation of the evolution and use of competency models. New Zealand Journal of Psychology ${ }_{2}$ New Zealand, v. 34, n. 2, p. 117126, 2005.

MARTINS, G. A.; THEÓPHILO, C. R. Metodologia da investigação científica para ciências sociais aplicadas. São Paulo: Atlas, 2007.

MCLAGAN, P. Competencies: the next generation.

Training and Development, United States of America, v. 51 , n. 5 , p. 40-47, 1997.

MISHLER, E. G. Validation in inquiry-guided research: the role of exemplars in narrative study. Harvard Business Education, Cambridge, v. 60, p. 415-442, 1990.
MILLS, J. et al. Competing through competences. Cambridge: Cambridge University Press, 2002.

MUNCK, L. Estratégia empresarial, aprendizagem e competências: análise de suas inter-relações em uma empresa de telecomunicações do Norte do Paraná. Tese (Doutorado em Administração). FEA - Universidade de São Paulo, São Paulo, 2005.

MUNCK, L.; MUNCK, M. M. Gestão de pessoas por competências em empresa pública: análise de repercussões nove anos pós-implantação. In: ENCONTRO DA ASSOCIAÇÃO NACIONAL DE PÓS-GRADUAÇÃO E PESQUISA EM ADMINISTRAÇÃO, 32., 2008, Rio de Janeiro. Anais... Rio de Janeiro: Anpad, 2008. p. 1-16.

MUNCK, L.; MUNCK; M. G. M.; BORIM-DE-SOUZA, R. Gestão de pessoas por competências: análise de repercussões dez anos pós-implantação. Revista de Administração da Mackenzie, São Paulo, v. 12, n. 1 , p. 4-52, 2011.

NORTH, K.; REINHARDT, K. Transparency and transfer of individual competencies: a concept of integrative competence management. In: 3rd INTERNATIONAL CONFERENCE ON KNOWLEDGE. Austria, 2003.

Anais... I-KNOW'03, Austria, 2003.

RICHARDSON, R. J. et al. Pesquisa social: métodos e técnicas. 3. ed. São Paulo: Atlas, 2008.

RUANO, A. M. Gestão por competências, uma perspectiva para a consolidação da gestão estratégica de recursos humanos. Rio de Janeiro: Qualitymark, 2003.

SHIPPMANN, J. S. et al. The practice of competency modeling. Personnel Psychology, United Kingdom, v. 53, p. 703-740, 2000.

SILVERMAN, D. Interpretação de dados qualitativos: métodos para análise de entrevistas, textos e interações. 3. ed. São Paulo: Artmed, 2009.

SMITH, R. Harnessing Competencies, Capabilities and Resources. Technology Management, United States of America, v. 51, n. 5, p. 47-53, 2008.

SPARROW, P. Organizational competencies: a valid approach for the future? International Journal of Selection and Assessment, United Kingdom, v. 3, n. 3, p. 168-177, 1995. 
Luciano Munck • Bárbara Galleli • Rafael Borim-de-Souza

SPENCER, L. M.; SPENCER, S. M. Competence at work. New York: John Willey \& Sons, 1993.

VIEIRA, M. M. F. Por uma boa pesquisa (qualitativa) em administração. In: VIEIRA, M. M. F; ZOUAIN, D. M. Pesquisa qualitativa em administração. Rio de Janeiro: FGV, 2006. p. 13-29. 